\title{
Bioactivities of Two Weeks White Yam (Dioscorea rotundata) Diet in Asthmatic Female Students in Relationship with Menstrual Cycle Using Luteinizing Hormone, Follicle-Stimulating Hormone, Glutathione Peroxidase and Superoxide Dismutase
}

\author{
Mathew Folaranmi OLANIYAN
}

Department of Medical Science, Achievers University, Owo-Nigeria

*Corresponding Author

Mathew Folaranmi OLANIYAN

Department of Medical Science

Achievers University

Owo-Nigeria

Cell no. $+2347033670802 ;+2348052248019$

Email: olaniyanmat@yahoo.com

Received: 27 October 2016; | Revised: 1 March 2017; | Accepted: 7 March 2017

\begin{abstract}
Severe clinical manifestations of asthma have been associated with menstrual cycle. Possible complication of asthma was reported to be infertility. White yam commonly used as food in South- West in Nigeria contains antioxidants and phytoestrogen. Aim and Objective: This work was designed to determine the bioactivities of two weeks white yam (Dioscorea rotundata) diet in asthmatic female students in relationship with mentrual cycle using luteinizing hormone, follicle-stimulating hormone, glutathione peroxidase and superoxide dismutase. Thirty nine asthmatic female students of Achievers University, Owo Nigeria aged 19-31 years on 28 days regular menstrual cycle were recruited through the University's health centre. Out of the thirty nine asthmatic female students 9 could not tolerate yam and green leafy vegetables for two weeks as a result of diarrhea, fourteen (14) were studied as test subjects fed yam and green leafy vegetables for the first two weeks of their 28 days regular menstrual cycle while the rest 16 asthmatic female students were studied as control subjects without yam and green leafy vegetables for the first two weeks of their 28 days regular menstrual cycle. Plasma level of Luteinizing hormone (LH), follicle-stimulating hormone (FSH), glutathione peroxidase (GPx) and superoxide dismutase (SOD) were determined biochemically by spectrophotometry and ELISA. The results obtained showed a significant reduction in the value of plasma GPx and SOD in asthmatic control students not fed on white yam at the mid cycle and also at the end of the third week of their menstrual cycle $(\mathrm{p}<0.05)$. This work also revealed a significantly higher plasma value of $\mathrm{LH}$ in the test after a 2 weeks of exclusive yam and vegetable meal than the control asthmatic female students at the end of 2 weeks of their menstrual cycle without yam and vegetable meal $(\mathrm{p}<0.05)$. Conclusion: White yam and green leafy vegetable supplement could reduce clinical manifestations and complications of asthma in asthmatic female students.
\end{abstract}


Keywords: Bioactivities, White Yam (Dioscorea rotundata), Asthmatic, Mentrual Cycle, Luteinizing Hormone, Follicle-Stimulating Hormone, Glutathione Peroxidase, Superoxide Dismutase

\section{Introduction}

Females experience changes in asthma control over the menstrual cycle, which include formation of vessel and regression controlled by angiogenic factors. In healthy females, menstrual cycle involves gas transfer which could be associated with angiogenesis and cyclic expansion of the pulmonary vascular bed. Asthmatic females experience cyclic changes in airflow as well as gas transfer and membrane diffusing capacity supportive of a hormonal effect on lung function [1].

Individuals suffering from asthma may experience health issues in major organs not connected to the respiratory system due to inflammation caused by asthma. . It has been reported by Thomsen et al., that women with asthma are, on average, less fertile than women without asthma [2]. Female hormones such as estrogen may have almost as much impact on the airways as allergies and hay fever. But estrogen itself is not the culprit in triggering the symptoms of asthma. Rather, the up and down of hormone levels -- that may cause inflammation in the airways. There is a complex interaction between fertility and asthma, women with asthma experienced longer waiting times to pregnancy [2][3]

Menstrual cycle hormones, such as Estrogen and progesterone can make asthma worse. Inflammation caused by asthma can affect other areas of the body not related to the respiratory system. This could explain why women who received treatment for asthma, usually antiinflammatory medication, were less likely to become infertile. "The inflammatory part of asthma may well be affecting not only bronchial tubes but also fallopian tubes," [2].

White Yams (Dioscorea rotundata) commonly eaten as food in Nigeria contains dioscin, Diosgenin, batatasin, allantoin, catecholamine; bastata sine-hydrochorde; protein, mannose: glucose: galactose, starch riboflavin, Vitamins $\mathrm{C}$,
B1, Barium, Beryllium, Cobalt, Chrome, Copper, Calcium, Polyphenoloxidase; holine, fiber, Carbohydrate, Carotene, mucilage, phytic acid. Yam (Dioscorea rotundata) belongs to the tuber family. True yams contain phytoestrogens, weak estrogens that will inhibit the body's own estrogen production in women who are estrogen dominant. Yams contain dioscin which is a form of natural progesterone. With women suffering from endometriosis and fibroids, both of which are linked to estrogen dominance, the phytoestrogens and progesterone like properties in yams can help regulate the estrogen progesterone balance [4].

The natural progesterone in yams can help extend the luteal phase in women whose corpus luteum does not produce enough progesterone causing early menstruation, or the so called luteal phase defect. It is believed that the phytoestrogens and progesterone-like properties in yams can help regulate the estrogen-progesterone balance. In theory the natural progesterone in yams can help extend the luteal phase in women whose corpus luteum does not produce enough progesterone causing early menstruation. The phytoestrogens in yams can counteract the effects of estrogen on the cervical fluid and make it too sticky for transport of sperm. They can also thin the endometrial lining, similarly to Clomid [4].

At exactly the first day of menstrual cycle the level of estrogen is at a low point. As a result, the pituitary secretes Follicle-Stimulating hormone (FSH) and Luteinizing Hormone ( $\mathrm{LH})$, A rise in follicle stimulating hormone (FSH) during the first days of the cycle stimulates few ovarian follicles. In follicular phase of the menstrual cycle, estradiol suppresses production of luteinizing hormone ( $\mathrm{LH})$ from the anterior pituitary gland. When eggs are almost matured, levels of estradiol reach a threshold above which this effect is reversed and estrogen stimulates the production of a large amount of LH(LH surge). This starts around day 12 of the average cycle and may last 48 hours. In females, FSH acts on the granulosa cells of the ovary to stimulate steroidogenesis, and to stimulate and sustain the development of a follicle leading up to 
ovulation. Menstrual cycle involves hormonal changes as mentioned which could serve as a triggers of asthmatic crisis [5][6].

Antioxidants are important for the body immune system and to protect the body against free radical attack. There are three levels of the body defense system (preventative antioxidants, scavenging antioxidants and repair enzymes). Significant amounts of superoxide dismutase (SOD) in cellular and extracellular environments are crucial for the prevention of diseases linked to oxidative stress. Mutations in SOD account for approximately $20 \%$ of familial amyotrophic lateral sclerosis (ALS) cases [7]. Glutathione peroxidase (GPx) catalyzes the reduction of hydroperoxides, including hydrogen peroxides, by reduced glutathione and functions to protect the cell from oxidative damage. Antioxidants are of immense health benefits which can reduce the discomforts experienced during menstrual cycle caused by hormonal changes [8].

In summary, asthma in females has been associated with infertility and menstrual cycle has also been linked with the severity of asthma. Considering the female hormonal nature of the phytochemicals in white yam, this work was designed to assess the bioactivities of two weeks white yam (Dioscorea rotundata) diet in asthmatic female students in relationship with mentrual cycle using luteinizing hormone (LH), folliclestimulating hormone (FSH), glutathione peroxidase (GPx) and superoxide dismutase (SOD).

\section{Material and Method}

\subsection{Study area}

Achievers University, Owo-Nigeria was established in 2007 and accredited by the National Universities Commission. It is located on land in the Idasen community of Owo, consisting of Ulale 1, Ulale 11, Ulema, Ijegunma, Isijogun and Amurin Elegba (formerly Amurin, Ogain).

\subsection{Study population}

Thirty nine asthmatic female students of Achievers University, Owo-Nigeria aged 19-31 years on 28 days regular menstrual cycle were recruited through the University's health center. Out of the thirty nine asthmatic female students 9 could not tolerate yam and green leafy vegetables for two weeks as a result of diarrhea, fourteen (14) were studied as test subjects fed yam and green leafy vegetables for the first two weeks of their 28 days regular menstrual cycle while the rest 16 asthmatic female students were studied as control subjects without yam and green leafy vegetables for the first two weeks of their 28 days regular menstrual cycle.

\subsection{Yam and Vegetable meal}

Many tubers of white yams were purchased from Oja Ikoko, Owo-Nigeria. The yams were identified by the Department of Biological Sciences, Achievers University, Owo-Nigeria. The asthmatic students volunteer studied as test subjects were on exclusive yam with vegetable sauce for the first two weeks of their menstrual cycle. The yams were eaten with green leafy vegetable as boiled or as a pounded yam employing local and traditional ways of cooking. The control asthmatic female students were placed on other meal apart from yam and vegetable.

\subsection{Biological specimen}

Five milliliters of venous fasting blood sample was obtained into lithium heparinized bottles from the test subjects before yam and vegetable meal on the first day of their menstrual cycle, at the end of two weeks yam and vegetable diet and also one week after two weeks of yam and vegetable meal. Five milliliters of venous fasting blood sample was obtained from the control subjects not on yam and vegetable meal on the first day of their menstrual cycle also at the end of second and third week of their menstrual cycle without yam and vegetable meal.

\subsection{Ethical Consideration}

Proposal of this work has been reviewed and approved by the Research and Ethical Committee, Department of Medical Laboratory Science, Achievers University, Owo-Nigeria.

\subsection{Method of Data Analysis}

The results obtained were subjected to statistical analysis using ANOVA by SPSS 18.0 to determine level of significance and variance at 0.05 . 


\subsection{Evaluation of plasma LH, FSH, SOD and GPx}

The plasma obtained from the lithium heparinized venous blood collected from test and control asthmatic female students was analysed for the concentration of LH and FSH and also for the activities of SOD and GPx as described below.

\subsection{Measurement of plasma LH using BIOKITS (www.bio-world.com)}

The LH Quantitative Test is based on a solid phase enzyme-linked immunosorbent assay (ELISA). The assay system utilizes a mouse monoclonalanti-alpha-LH antibody for solid phase (microtiter wells) immobilizationand a mouse

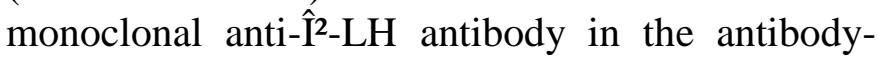
enzyme (horseradish peroxidase) conjugate solution. The test sample is allowed toreact simultaneously with the antibodies, resulting in LH molecules being sandwiched between the solid phase and enzyme-linked antibodies. After 45minute incubation at room temperature, the wells are washed with water to remove unbound-labeled antibodies. A solution of TMB Reagent is added and incubated for 20 minutes, resulting in the development of a blue color. The color development is stopped with the addition of Stop Solution, and the color is changed to yellow and measured spectrophotometrically at $450 \mathrm{~nm}$.

\subsection{Measurement of plasma Follicle Stimulating Hormone using BioAssay ${ }^{\mathrm{TM}}$ ELISA Kit (FSH)}

This FSH enzyme linked immunosorbent assay (ELISA) applies a technique called a quantitative sandwich immunoassay. The microtiter plate provided in this kit has been pre- coated with a monoclonal antibody specific for FSH. Standards or samples are then added to the microtiter plate wells and FSH if present will bind to the antibody pre-coated on the wells. In order to quantitate the amount of FSH present in the sample, a standardized preparation of horseradish peroxidase (HRP) conjugated monoclonal antibody specific for FSH is added to each well to "sandwich" the FSH immobilized on the plate. The microtiter plate undergoes incubation, and then the wells are thoroughly washed to remove all unbound components. Next, a TMB (3,3',5,5' Tetramethyl- benzidene) substrate solution is added to each well. This enzyme (HRP) and substrate are allowed to react over a short incubation period. Only those wells that contain FSH and enzyme-conjugated antibody will exhibit a change in colour. The enzyme substrate reaction is terminated by the addition of a sulphuric acid solution and the color change is measured spectrophotometrically at a wavelength of $450 \mathrm{~nm}$.

\subsection{Measurement of plasma SOD using Cayman Chemicals kit}

SOD activity is assessed by measuring the dismutation of superoxide radicals generated by xanthine oxidase and hypoxanthine in a convenient 96 well format. The standard curve generated using this enzyme provides a means to accurately quantify the activity of all three types of SOD $(\mathrm{Cu} / \mathrm{Zn}-, \mathrm{Mn}-$, and Fe-SOD). Each kit contains sufficient reagents to assay 41 samples in duplicate and includes assay buffer, sample buffer, radical detector, SOD (standard), xanthine oxidase, a 96 well plate, and complete instructions.

\subsection{Glutathione Peroxidase by Cayman Chemical Glutathione Peroxidase Assay Kit}

GPx activity is measured indirectly by a coupled reaction with glutathione reductase (GR). Oxidized glutathione (GSSG), produced upon reduction of an organic hydroperoxide by GPx, is recycled to its reduced state by GR and NADPH. The oxidation of NADPH to NADP+is accompanied by a decrease in absorbance at 340 $\mathrm{nm}$. The rate of decrease in the A340 is directly proportional to the GPx activity in the sample.

\section{Results}

As shown in Table 1, there was no significant variation in the value of LH, FSH, GPx and SOD in the plasma sample obtained as Basal, during two weeks of yam and vegetable meal and one week after yam and vegetable meal in Asthmatic patient feed with white yam and vegetable meal for two weeks ( $>0.05)$. There was no significant variation in the value of LH and FSH in the plasma sample obtained as Basal, after two weeks of menstrual cycle without yam and vegetable meal and at the 
end of the third week of menstrual cycle in asthmatic patient without white yam and vegetable meal for two weeks ( $>>0.05)$. There was a significant variation in the value of GPx and SOD in the plasma sample obtained as Basal, after two weeks of menstrual cycle without yam and vegetable meal and at the end of the third week of menstrual cycle in Asthmatic patient without white yam and vegetable meal for two weeks $(p<0.05)$.

As shown in Table 2, there was no significant difference in the comparative analysis of the basal values of plasma LH, FSH, SOD and GPx in asthmatic female students fed with yam and vegetable meal for two weeks and asthmatic female students that were not on yam and vegetable meal for three weeks $(\mathrm{p}>0.05)$.

As shown in Table 3, there was no significant difference in the comparative analysis of plasma value of LH, FSH, SOD and GPx after two weeks yam and vegetable meal in Asthmatic Female Students fed with the meal for two weeks compared with Asthmatic Female Students that were not on yam and Vegetable Meal ( $p>0.05)$, however, there was a significantly higher plasma value of $\mathrm{LH}$ in the test after a 2 weeks of exclusive yam and vegetable meal than the control asthmatic female students at the end of 2 weeks of their menstrual cycle without yam and vegetable meal $(\mathrm{p}<0.05)$.

As shown in Table 4, there was no significant difference in the comparative analysis of plasma value of LH, FSH, SOD and GPx at the end of one week after two weeks of yam and vegetable meal in asthmatic female students compared with asthmatic female students that were not on yam and vegetable meal but in their third week of menstrual cycle $(\mathrm{p}>0.05)$.

Table 1. Analysis of variance mean and standard deviation of plasma values of LH, FSH, SOD and GPx in the subjects

\begin{tabular}{|c|c|c|c|c|c|c|}
\hline \multirow[b]{2}{*}{ Group } & \multirow[b]{2}{*}{ Indicator } & \multirow[b]{2}{*}{$\begin{array}{l}\text { Basal } \\
\text { values }\end{array}$} & \multirow[b]{2}{*}{$\begin{array}{l}\text { Values after } 2 \\
\text { weeks of yam } \\
\text { and vegetable } \\
\text { sauce meal }\end{array}$} & \multirow{2}{*}{$\begin{array}{l}\text { Values after } \\
\text { one week of } 2 \\
\text { weeks of yam } \\
\text { and vegetable } \\
\text { sauce meal }\end{array}$} & \multicolumn{2}{|c|}{ ANOVA } \\
\hline & & & & & $\begin{array}{c}f \text {-ratio } \\
\text { value }\end{array}$ & $p$-value \\
\hline \multirow{4}{*}{$\begin{array}{c}\text { Asthmatic } \\
\text { Female students fed } \\
\text { with yam and } \\
\text { vegetable meal } \\
\mathrm{n}=19\end{array}$} & LH (IU/L) & $10 \pm 5.0$ & $19 \pm 3.0$ & $14 \pm 3.0$ & 1.42 & 0.37 \\
\hline & FSH (mlU/ml) & $5 \pm 2$ & $12 \pm 1.5$ & $9 \pm 1.0$ & 5.1 & 0.11 \\
\hline & SOD (ng/ml) & $100 \pm 6.0$ & $96 \pm 10$ & $75 \pm 9$ & 2.50 & 0.23 \\
\hline & GPx(U/L) & $233 \pm 13$ & $200 \pm 10$ & $185 \pm 6.0$ & 5.9 & 0.09 \\
\hline \multirow{4}{*}{$\begin{array}{c}\text { Asthmatic } \\
\text { Female students } \\
\text { without yam and } \\
\text { vegetable meals } n=20\end{array}$} & LH (IU/L) & $11 \pm 3$ & $7 \pm 2.0$ & $10 \pm 3$ & 0.25 & 0.80 \\
\hline & FSH (mlU/ml) & $6 \pm 2$ & $10 \pm 1$ & $6 \pm 2$ & 1.8 & 0.3 \\
\hline & $\mathrm{SOD}(\mathrm{ng} / \mathrm{ml})$ & $98 \pm 5$ & $82 \pm 2$ & $66 \pm 5$ & 14.2 & 0.03 \\
\hline & GPx (U/L) & $241 \pm 10$ & $180 \pm 8$ & $168 \pm 5$ & 24.3 & 0.01 \\
\hline
\end{tabular}


Table 2. Comparative analysis of the basal values of plasma LH, FSH, SOD and GPx in asthmatic female students fed with yam and vegetable meal for two weeks and asthmatic female students that were not on yam and vegetable meal for three weeks

\begin{tabular}{|c|c|c|}
\hline \multirow{2}{*}{ Indicator } & Basal values & $\begin{array}{c}\text { Asthmatic female students fed with yam and vegetable meal } \\
(\mathrm{n}=14) \text { Vs Asthmatic female students without yam and } \\
\text { vegetable meal (n=16) }\end{array}$ \\
\hline \multirow{2}{*}{ LH (IU/L) } & "t" & -0.27 \\
\cline { 2 - 3 } & "p" & 0.41 \\
\hline \multirow{2}{*}{ FSH (m IU/ml) } & "t" & -0.35 \\
\cline { 2 - 3 } & "p" & 0.38 \\
\hline \multirow{2}{*}{ SOD (ng/ml) } & "t" & 0.26 \\
\cline { 2 - 3 } & "p" & 0.41 \\
\hline \multirow{2}{*}{ GPx (U/L) } & "t" & -0.63 \\
\cline { 2 - 3 } & "p" & 0.30 \\
\hline
\end{tabular}

Table 3. Comparative analysis of plasma value of FSH, SOD and GPx after two weeks yam and vegetable meal in asthmatic female students fed with the meal for two weeks and asthmatic female students that were not on yam and vegetable Meal

\begin{tabular}{|c|c|c|}
\hline \multirow{2}{*}{ Indicator } & $\begin{array}{c}\text { Values after exclusive 2 } \\
\text { weeks of yam and vegetable } \\
\text { sauce meal }\end{array}$ & $\begin{array}{c}\text { Asthmatic female students fed with yam and vegetable meal } \\
(\mathrm{n}=14) \text { Vs Asthmatic female students without yam and } \\
\text { vegetable meal (n=16) }\end{array}$ \\
\hline \multirow{2}{*}{ LH (IU/L) } & "t" & 3.33 \\
\cline { 2 - 3 } & "p" & 0.04 \\
\hline \multirow{2}{*}{ FSH (m IU/ml } & "t" & 0.90 \\
\hline \multirow{2}{*}{ SOD (ng/ml) } & "p" & 0.23 \\
\cline { 2 - 3 } & "t" & 1.40 \\
\hline \multirow{2}{*}{ GPx (U/L) } & "p" & 0.15 \\
\cline { 2 - 3 } & "p" & 1.60 \\
\hline
\end{tabular}

Table 4. Comparative analysis of plasma value of LH, FSH, SOD and GPx one week after two weeks of yam and vegetable meal in asthmatic female students compared with asthmatic female students that were not on yam and vegetable meal in their third week of menstrual cycle

\begin{tabular}{|c|c|c|}
\hline \multirow{2}{*}{ Indicator } & $\begin{array}{c}\text { Values after one week of 2 } \\
\text { weeks of yam and vegetable } \\
\text { sauce meal }\end{array}$ & $\begin{array}{c}\text { Asthmatic female students fed with yam and vegetable meal } \\
(\mathrm{n}=14) \text { Vs Asthmatic female students without yam and } \\
\text { vegetable meal (n=16) }\end{array}$ \\
\hline \multirow{2}{*}{ LH (IU/L) } & "t" & 0.94 \\
\cline { 2 - 3 } & "p" & 0.22 \\
\hline \multirow{2}{*}{ FSH (m IU/ml) } & "t" & 1.34 \\
\hline \multirow{2}{*}{ SOD(ng/ml) } & "p" & 0.16 \\
\cline { 2 - 3 } & "t" & 0.87 \\
\hline \multirow{2}{*}{ GPx(U/L) } & "p" & 0.24 \\
\cline { 2 - 3 } & "t" & 2.2 \\
\hline
\end{tabular}




\section{Discussion}

This work was used to determine the effect of 2 weeks of yam meal in asthmatic female students in relationship with their 28 days regular menstrual cycle.

There was a significant variation in the value of GPx and SOD in the plasma sample obtained as Basal, after two weeks of menstrual cycle without yam and vegetable meal and at the end of the third week of menstrual cycle in Asthmatic patient without white yam and vegetable meal for two weeks. There was a significant reduction in the value of plasma GPx and SOD in asthmatic control students at the mid cycle and also at the end of the third week of the menstrual cycle. This could be as a result of possible oxidative stress around ovulation period due to hormonal changes as menstrual cycle hormones can make asthma worse. Inflammation caused by asthma can affect other areas of the body not related to the respiratory system. This could explain why women who received treatment for asthma, usually antiinflammatory medication, were less likely to become infertile. The inflammatory part of asthma may well be affecting not only bronchial tubes but also fallopian tubes [2].This significant biochemical changes was not found in asthmatic female students fed on white yam and vegetable for the first two weeks of their 28 days menstrual cycle. This is could be attributed to phytochemical antioxidants present in both white yam and the green leafy vegetable. The body of asthmatic female students that were not fed with yam and vegetable meal might have excessively utilized antioxidant such as SOD and GPx resulting into significant decrease in their activities around the period of ovulation.

However, a significantly higher plasma value of LH was obtained in the test after 2 weeks of exclusive yam and green leafy vegetable meal than the control asthmatic female students at the end of 2 weeks of their menstrual cycle without yam and vegetable meal. This could be due to $\mathrm{LH}$ surge at ovulation period. The process of ovulation is controlled by the hypothalamus of the brain and through the release of hormones secreted in the anterior lobe of the pituitary gland, luteinizing hormone (LH) and follicle-stimulating hormone (FSH) [9]. In the pre-ovulatory phase of the menstrual cycle, the ovarian follicle will undergo a series of transformations called cumulus expansion, which is stimulated by FSH. After this is done, a hole called the stigma will form in the follicle, and the secondary oocyte will leave the follicle through this hole. Ovulation is triggered by a spike in the amount of FSH and LH released from the pituitary gland [10].

In addition this significant increase in $\mathrm{LH}$ concentration in test female asthmatic students than the control asthmatic female students could be interpreted considering the phytochemical constituent of true yams that contain phytoestrogens, weak estrogens that will inhibit the body own estrogen production in women who are estrogen dominant. Yams also contain a form of natural progesterone (dioscin). The phytoestrogens and progesterone like properties in yams can help regulate the estrogen progesterone balance [4][11]. Phytoestrogens is a natural estrogen in yam. Estrogen levels peak towards the end of the follicular phase. This causes a surge in levels of luteinizing hormone (LH) and follicle-stimulating hormone (FSH) which could be associated with the raised plasma $\mathrm{LH}$ in the asthmatic female test subjects[4][11]..

Furthermore, the natural progesterone in yams can help extend the luteal phase in women whose corpus luteum does not produce enough progesterone causing early menstruation, or the so called luteal phase defect. It is believed that the phytoestrogens and progesterone-like properties in yams can help regulate the estrogen-progesterone balance which could contribute to a significant increase in LH found in the test subject of this work [4].

This could also be attributed to possible fertility properties of white yam which could be a supplement due to natural progesterone and phytoestrogens constituents in treating infertility a complication of asthma as it has been reported that women with asthma are, on average, less fertile than women without asthma [2]. There is also a complex interaction between fertility and asthma, women with asthma experienced longer waiting times to pregnancy [2][3].

Progesterone with plant phytoestrogens will reduce the intense symptoms and discomfort of menopause, per-menopause and other hormonal 
imbalances without the side effects associated with synthetic chemically derived hormone replacement therapy. Phytoestrogens are plant-derived xenoestrogens not generated within the endocrine system but consumed by eating phytoestrogenic plants such as white yam [12] [13].

They are a diverse group of naturally occurring nonsteroidal plant compounds that, because of their structural similarity with estradiol (17- $\beta$-estradiol), have the ability to cause estrogenic or/and antiestrogenic effects, by sitting in and blocking receptor sites against estrogen. Estradiol, or more precisely, 17 $\beta$-estradiol, is a steroid and estrogen sex hormone, and the primary female sex hormone. It is named for and is important in the regulation of the estrous and menstrual female reproductive cycles. Estradiol is essential for the development and maintenance of female reproductive tissues [14][15].

\section{Conclusion}

There was a significant reduction in the value of plasma GPx and SOD in asthmatic control students not fed on white yam at the mid cycle and also at the end of the third week of the menstrual cycle. This work also revealed a significantly higher plasma value of LH in the test after 2 weeks of exclusive yam and vegetable meal than the control asthmatic female students at the end of 2 weeks of their menstrual cycle without yam and vegetable meal.

\section{Recommendation}

White yam and green leafy vegetable could serve as a supplement to reduce clinical manifestations and complications of asthma in female.

\section{References}

1. Samar Farha, Kewal Asosingh, Daniel Laskowski, Jeffrey Hammel, Raed A. Dweik, Herbert P. Wiedemann, and Serpil C. Erzurum Effects of the Menstrual Cycle on Lung Function Variables in Women with AsthmaAm J Respir Crit Care Med. 2009 Aug 15; 180(4):
304-310. Published online 2009 Jun 11. DOI: 10.1164/rccm.200904-04970C

2. Thomsen S, Lindenburg S, Kyvik K, Lieberoth S, Backer V, Gade E. "Asthma affects time to pregnancy and fertility: a register-based twin study." European Respiratory Journal. 2013

3. Elisabeth J Gade, Simon F Thomsen, Svend Lindenberg, Kirsten O Kyvik, Sofie Lieberoth, and Vibeke Backer Asthma affects time to pregnancy and fertility: a register-based twin study. European Respiratory Journal, 2014; 43(4):1077 (2014) PMID 24232708

4. Eleazu CO, Kolawole S, Awa E Phytochemical Composition and Antifungal Actions of Aqueous and Ethanolic Extracts of the Peels of 2 Yam Varieties. Med Aromat Plants 2013; $2: 128$.

5. Batzer F. R. Hormonal evaluation of early pregnancy.Fertility and Sterility 1980; 34(1) 1-13 DOI: 10.1016/S0015-0282(16)44829$\underline{6}$

6. Lenton E. A., L. M. Neal and R. Sulaiman. Plasma concentrations of human chorionic gonadotropin from the time of implantation until the second week of pregnancy. Fertility and Sterility 37(6) 773-778 (1982). DOI: 10.1016/S0015-0282(16)46337-5

7. Maier C. M. and Chan . P. H. Role of superoxide dismutases in oxidative damage and neurodegenerative disorders. Neuroscientist, 2002; $\quad 8(4) \quad 323-334 . \quad$ DOI: 10.1177/107385840200800408

8. Ceballos-Picot, J. M. , A. Nicole, et al. Agecorrelated modifications of copper-zinc superoxide dismutase and glutathione-related enzyme activities in human erythrocytes. Clinical Chemistry 1992; 38 66-70

9. Marieb, Elaine. Anatomy \& physiology. Benjamin-Cummings. 2013 p. 915. ISBN 9780321887603.

10. Young, Barbara. Wheater's Functional Histology: A Text and Colour Atlas (5th ed.). Elsevier Health Sciences 2006; . p. 359. ISBN 9780443068508. Retrieved 2013-11-09.

11. Chaudhuri, S.K. "Natural Methods of Contraception". Practice of Fertility Control: A Comprehensive Manual, 7/e.Elsevier India. 2007; p. 49. ISBN 9788131211502. 
Retrieved 2013-11-09.doi:10.4172/21670412.1000128Copyright

12. Yildiz F. Phytoestrogens in Functional Foods. Taylor \& Francis Ltd.2005; pp. 3-5, 210-211. ISBN 978-1-57444-508-4. DOI: 10.1201/9781420027594

13. Zhao E, Mu Q "Phytoestrogen biological actions on Mammalian reproductive system and cancer growth". Scientia Pharmaceutica. 2011; 79

$1-20$. doi:10.3797/scipharm.1007-15. PMC
14. Ryan KJ. "Biochemistry of aromatase: significance to female reproductive physiology". Cancer Res.1982; 42 (8 Suppl): 3342s-3344s. PMID 7083198.

15. Pentikäinen V, Erkkilä K, Suomalainen L, Parvinen M, Dunkel L. "Estradiol acts as a germ cell survival factor in the human testis in vitro". The Journal of Clinical Endocrinology and Metabolism. 2000; 85 (5): 2057-67. doi:10.1210/jcem.85.5.6600. PMID 10843196. DOI: 10.1016/0140-6736(91)92168-2 3097497 free to read. PMID 21617769. 